\title{
CURSO NORMAL RURAL DO COLÉGIO NOSSA SENHORA AUXILIADORA DE PETROLINA (1929-1989): Um Marco na História da Formação Docente
}

\author{
Rosa Santos Mendes da Silva ${ }^{1}$ \\ Edmerson dos Santos Reis ${ }^{2}$
}

\begin{abstract}
RESUMO
Neste trabalho apresentamos uma trajetória histórica do curso Normal Rural do Colégio Nossa Senhora Auxiliadora. Essa Instituição enquadra-se dentro de uma perspectiva de ensino confessional, mantida pela congregação das filhas de Maria Auxiliadora, com base nos conceitos cristãos, fundada na primeira metade do século 20. Com relação aos aspectos teórico-metodológicos, a pesquisa baseou-se na análise histórico-documental e pesquisa de campo, tendo como base o recorte temporal de 1929 a 1989, período que abrange desde a criação do curso Normal Rural até o ano em que ocorreu oficialmente a sua extinção. Foi possível apreender que, no Estado de Pernambuco, a primeira "Escola Normal Rural" foi a do Colégio Nossa Senhora Auxiliadora no ano de 1936. Assim, a educação do Curso Normal esteve associada às ideias de cristianização da Igreja Católica e atendeu aos anseios da sociedade da época.
\end{abstract}

Palavras-chave: Curso Normal Rural. Educação confessional. Formação docente.

RURAL NORMAL COURSE OF THE COLLEGE OUR LADY HELPER HIGH SCHOOL DE PETROLINA (1929-1989): A MILESTONE IN THE HISTORY OF TEACHER TRAINING

\section{ABSTRACT}

In this paper we present a historical trajectory of the Normal Rural Course of Colégio Nossa Senhora Auxiliadora. This Institution fits within a perspective of confessional teaching, maintained by the congregation of the daughters of Mary Help of Christians, constituted by Christian concepts, founded in the first half of the 20th century. Regarding the theoretical and methodological aspects, the research was based on historical document analysis and field research, based on the period of the decades from 1929 to 1989, a period that ranges from the creation of the normal rural course until the year in which there was officially its extinction. It was possible to apprehend that in the state of Pernambuco the first "Normal Rural School" was that of Colégio Nossa Senhora Auxiliadora in 1936. Thus, the education of the Normal Course was associated with the ideas of Christianization of the Catholic Church and met the wishes of the society of the time.

Keywords: Normal Rural Course. Confessional education. Teacher training.

Recebido em: $20 / 4 / 2020$

Aceito em: $13 / 1 / 2021$

\footnotetext{
1 Autora correspondente. Universidade de Pernambuco. Avenida Avelino dos Santos - Pedra Linda. CEP 56317190 - Petrolina/PE, Brasil. http://lattes.cnpq.br/1090128522905709. https://orcid.org/0000-0002-6245-402X. rosa.sns@hotmail.com

2 Universidade do Estado da Bahia - Departamento de Ciências Humanas III. Juazeiro/BA, Brasil. http://lattes.cnpq.br/4799013495727395. http://orcid.org/0000-0003-3153-6759.
} 
Este texto analisa a história do curso Normal Rural de público feminino, ocorrido no período de 1929-1989, curso este oferecido em regimes de internato, externato e semi-internato pelo Colégio Nossa Senhora Auxiliadora (CNSA). Uma escola confessional, católica e privada, situada na cidade de Petrolina - PE, o que representa, de acordo com Lugli (2002, p. 8), “[...] um passo importante no processo de formação, uma vez que não mais se aceitavam pessoas sem os conhecimentos específicos para atuar no ensino, embora isso ainda tenha permanecido nas décadas posteriores, porém, em número menor".

O Colégio Nossa Senhora Auxiliadora foi uma escola idealizada e fundada pelo primeiro Bispo de Petrolina, Dom Antônio Malan, em 1926, organizada e mantida pela diocese dessa cidade. Diante do contexto histórico e social da instituição, período em que acontecia a Segunda Guerra Mundial, Ramos (2016) afirma que:

No ano de 1946, o mundo ainda sofria com o término da Segunda Guerra Mundial. A Região São Franciscana também foi impactada com os resquícios deste cruel período, todos reforçando consolos, carinho, espiritualidade, recorrendo a Deus. As irmãs salesianas, com suas presenças na região já há vinte anos, trazidas por Dom Malan, estão felizes, porque mais jovens de Juazeiro unem-se ao seu rebanho, com estudo, com religiosidade, descobrindo também vocações, preparando mulheres para um futuro promissor de serem professoras (RAMOS, 2016, p. 13).

Nessa direção, segundo Carvas (2015, p. 11), “[...] formar professoras com base nos preceitos católicos e na pedagogia salesiana era a grande preocupação das Escolas Normais, que viam a formação de suas alunas como a chave para dar continuidade à sua ação educativa e religiosa na sociedade".

Assim sendo, a autora ainda destaca que as congregações católicas ofereciam uma formação que era fortemente marcada pela religiosidade no espaço escolar, o que reafirmava a tradição de caracterizar a docência como um trabalho missionário e sacerdotal.

A criação de colégios femininos contribuiu para a entrada da mulher no mercado de trabalho, por meio de uma profissão legitimada perante a sociedade. Santos (2006, p. 91) lembra "[...] que esse nível de ensino era considerado a meta mais alta dos estudos a que uma jovem poderia almejar". As Escolas Normais se revelaram como uma das poucas oportunidades que as mulheres tinham de ultrapassar o ensino primário.

Este estudo sobre as referidas Escolas Normais se justifica também pela possibilidade de se conhecer o passado e estabelecer relações com o presente, a partir das memórias de professores e professoras. Como lembra Le Goff (1994, p. 477 apud Rocha 2014, p. 6), “[...] é da análise e interpretação dos registros, da memória, que se reconstitui a história, que, por sua vez, procura salvar o passado para servir o presente e o futuro".

De acordo com essa percepção, e também pela crença dos envolvidos neste trabalho, no papel relevante do professor na escolarização da infância na zona rural, buscou-se compreender nas memórias do passado as motivações para a escolha da profissão, bem como a complexidade e heterogeneidade das condições do trabalho docente no período em tela. 
Nesse sentido, com a criação dos dois primeiros colégios particulares em Petrolina, o Colégio Nossa Senhora Auxiliadora para o público feminino e o Colégio Dom Bosco destinado aos meninos, os estudantes de Juazeiro.- BA, devido às deficiências do sistema de educação naquela cidade, iam estudar em Petrolina. Para Brito (1995, p. 269), "[...] embora fosse um pequeno número de alunos que completava os cursos primários e secundários relativos oriundos de outras cidades do Nordeste, especialmente, as do interior, Petrolina apresentava grande número de diplomados".

Partimos da hipótese de que, em virtude de o colégio ser católico, confessional e privado, a proposta educacional da instituição pautou-se numa pedagogia do evangeIho, portanto tanto o currículo como as práticas pedagógicas e disciplinares almejavam possibilitar uma formação moral e religiosa, sendo esta a missão educativa das Filhas de Maria Auxiliadora para as normalistas. Outra hipótese levantada é que o trabalho educacional da instituição correspondia aos anseios da sociedade da época, ou seja, oferecer uma formação profissional, moral e educacional.

A relevância social deste estudo para a história da educação partiu do propósito de mostrar para a comunidade escolar e científica local a importância das Escolas Normais, desde a sua institucionalização até a contribuição para a formação dos professores.

Os procedimentos metodológicos desta pesquisa basearam-se na análise histórico-documental e na pesquisa de campo, com a investigação sendo conduzida a partir do estudo histórico, pois entendemos que essa viagem é inerente à natureza de um estudo que objetiva conciliar o passado com a história para melhor compreensão do assunto.

Assim, para melhor alcançar o entendimento do curso Normal Rural do CNSA, a pesquisa se fez a partir da investigação das fontes documentais da instituição, tais como: livro de registro; o livro "A união das ex-alunas salesianas através do tempo: um recorte histórico", produzido por Lusinete Ramos, ex-aluna do curso; os arquivos dos jornais O Pharol e O Sertão; fotos, além de outros periódicos. A partir do contato com os documentos foi possível buscar resultados necessários para o aprofundamento da pesquisa, oferecendo subsídios para compreender a criação da instituição, bem como os elementos arquitetônicos do prédio onde funcionou o curso Normal Rural e entender também como se dava a formação das normalistas a partir do currículo desta escola, na medida em que ela surgiu com um diferencial por ser uma escola normal rural.

O artigo está organizado em três partes, incluindo "Introdução", na qual apresentamos o trabalho de forma geral. A segunda parte, "Reflexões Acerca da Escola Normal no Brasil: aspectos históricos", coloca em relevo um breve estudo sobre a escola normal no Brasil, destacando o papel e os aspectos básicos das escolas normais na transição do século 19 para o 20.

Na terceira parte "Curso Normal Rural: instalação e sujeitos", são apresentados os resultados da pesquisa, trazendo abordagens sobre a história da escola normal rural do Colégio Nossa Senhora Auxiliadora, enfatizando a chegada das primeiras irmãs salesianas na cidade de Petrolina - PE, e os desafios enfrentados na consolidação do trabalho desenvolvido na educação. Ademais, discorremos sobre a abertura oficial do curso Normal Rural. Finalmente, nas "Considerações Finais", retomamos as questões propostas 
pela pesquisa, realizando a análise de todo o percurso alcançado na tentativa de somar, junto com outros estudos, a compreensão da formação docente no município de Petrolina, esclarecendo o trabalho desenvolvido pelo CNSA.

\section{REFLEXÕES ACERCA DA ESCOLA NORMAL NO BRASIL: Aspectos Históricos}

Durante o processo histórico de consolidação da Escola Normal, diversos fatores sociais, econômicos e culturais colaboraram para formatar e destinar a esse ramo de ensino a tarefa de formar professores para o magistério primário.

Na transição do século 19 para o 20 alguns critérios foram articulados em razão de uma melhor organização na estrutura da formação do professor:

Outro marco fundamental, nesse cenário foi a substituição do docente pelo corpo docente laico sob o controle do Estado, e que vai demandar o aperfeiçoamento dos instrumentos e das técnicas pedagógicas, bem como a elaboração de um corpo de saberes específicos. O ensino torna-se, assim, assunto de especialistas e a ética docente, no início ligado à vida religiosa, passa à prática de um ofício/profissão (VASCONCELOS, 2004 apud NETO, 2016, p. 10).

A Escola Normal passa a cumprir, dessa forma, um papel fundamental na constituição da profissão docente. A partir dela, como ressalta o autor, configura-se o novo professor, deixando para trás o velho mestre-escola do ensino primário.

Fazer um Curso Normal não era, como hoje, permanecer durante um número definido de anos estudando um conjunto de disciplinas lecionadas por especialistas para obter um diploma. Essas escolas foram, até meados do século 19, estabelecimentos a cargo de um único professor que lecionava a totalidade das matérias (VICENTINI; LUGLI, 2009).

No Brasil, a formação de docentes para o ensino das primeiras letras em cursos específicos foi proposta no final do século 19

com a criação das Escolas Normais. Logo após a promulgação da 1a Lei da Instrução Pública, no 38.398 em 15 de outubro de $1827^{3}$ e do Ato adicional de 1834, foi criada a primeira Escola Normal brasileira na Província do Rio de Janeiro, pela Lei $\mathrm{n}^{\circ} 10$, de 1835 (VICENTINI; LUGLI, 2009, p. 60).

Nos anos que se seguiram à criação da primeira Escola Normal, conforme atestam os estudos de Leonor Tanuri, a experiência se repetiu em outras províncias, a saber:

[...] em Minas Gerais, em 1835 (instalada em 1840); na Bahia, em 1836 (instalada em 1841); em São Paulo, no Piauí, em 1864 (instaladas em 1865); em Alagoas, em 1864 (instalada em 1869); em São Pedro do Rio Grande do Sul, em 1869; no Pará, em 1870 (instalada em 1871); em Sergipe, em 1870 (instalada em 1871); no Amazonas, em 1872, no Rio Grande do Norte, em 1873 (instalada em 1874); no Maranhão, em 1874, com a criação de uma Escola Normal particular, subvencionada

A lei assim determinava, que: "em todas as cidades, vilas e lugares mais populosos, haverão as escolas de primeiras letras que fossem necessárias" (Art. $1^{\circ}$ ). Disponível em http: www.planalto.gov.br/ccivil_03/leis LIM/LIM-15-101827htm. Acesso em: 13 maio 2016. 
pelo governo; na Corte, em 1874, também com a criação de uma Escola Normal particular, subvencionada pelo governo, e em 1876 com a criação de uma Escola Normal pública (instalada apenas em 1880); no Paraná, em 1876; em Santa Catarina, em 1880; no Ceará, em 1880 (instalada em 1884) (Moacyr, 1939a, 1939b, 1940); no Mato Grosso, em 1874 (Siqueira, 1999, p. 210); em Goiás, em 1882 (instalada em 1884) (TANURI, 2000, p. 64).

Nessa perspectiva, a autora destaca que todas essas escolas eram de responsabilidade dos governos provinciais, ou seja, significando que elas foram abertas por opção dos dirigentes de cada Estado e estavam condicionadas à disponibilidade de verbas, sempre escassas, tendo em vista as dificuldades materiais que todas enfrentavam. A precariedade da estrutura fez com que esse tipo de ensino tivesse, durante muito tempo, uma existência incerta, pois, apesar das tentativas de atração de alunas novas, a não admissão de mulheres em número suficiente para manter-se em atividade terminava por comprometer o funcionamento.

Tanuri (2000, p. 19) ressalta: “[...] que foram frequentes, até meados do século $\mathrm{XIX}$, as notícias de fechamentos e reaberturas sucessivas dos poucos cursos existentes no país".

Nesse sentido, cita como exemplo o caso da Escola Normal de São Paulo: aberta em 1846, fecha em 1867, reabre em 1876 e fecha novamente em 1877, reabrindo ainda outra vez em 1880, ou seja, o que representou uma baixa procura pelos cursos de formação de professores e o desprestígio desse trabalho associado à baixa remuneração dos profissionais.

No século 20, com a Lei Orgânica do Ensino Normal de 1946, ${ }^{4}$ o Ministério da Educação procurou dar uma organização nacional à formação de professores, bem como regular a sua articulação com os demais tipos e níveis de ensino, tal como fora definido pela Constituição de 1937, na qual se estabeleceu que a União deveria organizar o ensino em todos os níveis no país.

Os modos de organizar e administrar o ensino permaneceu dessa forma durante boa parte do século 20 . Vicentini e Lugli $(2009$, p. 30$)$ afirmam que: “[...] soma-se a isso o fato de que as escolas e os cargos de professores se constituíram em moeda de troca nos jogos políticos locais, o que dava impulso à defesa da autonomia federativa frente ao poder central".

Em Pernambuco, somente em 1864, com a criação da primeira Escola Normal Oficial, na cidade de Recife, instalada em 1865, estabelece-se um marco na institucionalização da formação docente:

Para ingressar na escola o(a) candidato(a) deveria saber ler, escrever, contar, ter 18 anos de idade e bons costumes. Havia um pequeno número de habilitados pela Escola Normal e uma quantidade expressiva de provimento de professores por contrato, de professores interinos no interior que possuíam ou não algum tipo de habilitação profissional, como atestam as reclamações dos relatórios oficiais (PERES, 2006, p. 10).

BRASIL (1946). 
Com base no entendimento anterior, é importante refletir que a ampliação da formação docente no sertão de Pernambuco exigia pouco, ou seja, apenas o conhecimento básico para o exercício docente no ensino em escolas primárias.

Do ponto de vista da Lei 1.836 da Província de Pernambuco, estabeleceram-se critérios para a contratação de professores, conforme analisa Peres (2006):

Estes deveriam estar preparados na aplicação do método mútuo a ser devidamente examinados, sendo que em 1827 foi promulgada a primeira Lei Orgânica do ensino no Brasil, mas, em Pernambuco, essa lei foi instituída em 1837, com o principal objetivo na ampliação dos deveres e direitos aos professores. Mas, foi somente a partir de 1855, que se configurou um maior volume de intervenções legais, estabelecendo um conjunto de normas e intenções, que se procurou uma organização de uma profissão responsável pela direção dos trabalhos de ensino (p. 13).

Nesse sentido, observa-se as exigências postas para a contratação de professores, no que se refere à atuação no ensino público primário, tendo como foco atender os critérios configurados na legislação, no intuito de uma maior organização do trabalho docente.

No que se refere à Lei Orgânica do Ensino Normal ${ }^{5}$ de 1946, esta procurou dar uma organização nacional à formação de professores, bem como regular a sua articulação com os demais tipos e níveis de ensino:

Tal como fora definido pela Constituição de 1937, na qual se estabelecera que a União devesse organizar o ensino em todos os níveis no país. A estrutura da formação dos professores com essa lei ficou dividida em dois ciclos: o primeiro seria de quatro anos, com o intuito de formar professores para atuar no ensino primário em instituições denominadas Escolas Normais Regionais e o segundo seria de três anos, destinado à formação do professor primário para as escolas normais e nos Institutos de Educação (VICENTINI; LUGLI, 2009, p. 46).

Diante desse panorama, a lei preveniu mudanças à estrutura do Ensino Normal, organizou suas relações com os demais níveis e ramos do ensino, uma vez que articulou o ensino primário com o primeiro ciclo do ensino. Isso significa que para se inscrever no exame de admissão do curso era preciso ter prova de conclusão dos estudos primários e idade mínima de 13 anos.

Quanto à década de 50, houve uma expansão considerável do Ensino Normal, cujas matrículas cresceram 150\% entre os anos de 1951 e 1960.

Esse crescimento ocorreu predominantemente na rede de ensino particular, uma vez que mais de dois terços dos cursos normais secundários no Brasil nesse período eram particulares e concentravam-se nos estados de São Paulo e Minas Gerais. É importante observar que, embora o número de Escolas Normais oficiais fosse reduzido, tendo em vista as necessidades de professores formados, havia um número considerável de Escolas Normais de iniciativa particular, que não eram submetidas ao controle e à fiscalização do Estado. Isso significava também que seus diplomas

BRASIL. Decreto-Lei no 8.530, de 2 de Janeiro de 1946. Institui a Lei Orgânica do Ensino Normal. Diário Oficial, Rio de Janeiro, 1946. Disponível em: http://www2.camara.leg.br/legin/fed/declei/1940-1949/decreto-lei-8530-2janeiro-1946-458443-publicacaooriginal-1-pe.html. Acesso em: 24 maio 2016. 
não possuíam validade oficial. Para que os diplomas desses estabelecimentos particulares tivessem alguma validade para prestar concurso público, era preciso que estes se submetessem à inspeção oficial que, ao verificar a existência de condições próprias de funcionamento, atribuía a esses cursos a condição de equiparados aos cursos normais públicos e, num período posterior, autorizava o seu funcionamento (TANURI, 2000, p. 46).

Para a autora, o crescimento do Ensino Normal particular no país passou por um processo crescente, entretanto havia dificuldades no que se refere ao ingresso dos profissionais formados por este segmento no mercado de trabalho, principalmente pela via dos concursos públicos, pois muitas dessas escolas não recebiam o controle de fiscalização do Estado. Assim, apesar da necessidade de professores, a validação oficial dos diplomas era difícil, uma vez que essas escolas precisariam de inspeção federal para que pudessem emitir diplomas equiparados aos cursos normais públicos de formação de professores. Em muitos casos, os cursos sem inspeção oficial pareciam caracterizar-se por baixa exigência com relação à qualidade do ensino, que ao se combinar com um controle ineficaz por parte do poder público, os efeitos eram perversos com relação ao preparo dos professores primários.

Durante a década de 60 foram criados os Cursos Normais noturnos, que seguiam o mesmo currículo e estrutura dos cursos diurnos, mas geravam grandes perdas em termos do rendimento dos estudos realizados. Segundo Tanuri (2000, p. 46), "[...] os alunos vinham cansados para as aulas e, portanto, tinham menos condições de aprender o que era ensinado e de se realizarem os estágios necessários para a formação prática, pois as escolas regulares que recebiam para os referidos estágios funcionavam apenas em período diurno".

Nesse viés, explica a autora, que o currículo da Escola Normal passou a ser objeto de críticas, uma vez que a aproximação entre esse curso e o ginásio colegial, processada a partir da Lei Orgânica de 1946 e completada em 1971, descaracterizava as funções de preparo profissional das normalistas. A preparação de professores passou de um curso em dois níveis, destinado exclusivamente à formação profissional, para um curso secundário de caráter geral com algumas disciplinas de formação específica.

Ainda na década de 60 as Escolas Normais começaram a ter sua qualidade de ensino questionada, tendo sido identificadas muitas vezes como cursos de formação geral para moças e futuras donas de casa, ao invés de cursos de profissionalização docente. De acordo com Vicentini e Lugli (2009, p. 222):

A esse desprestígio, aliaram-se as dificuldades salariais dos professores, acentuadas desde o governo de Juscelino Kubitschek, quando a inflação impôs a diminuição do poder aquisitivo da categoria. Essa foi uma situação paradoxal porque a tão almejada formação específica exigia por parte dos professores o investimento na compra de livros e na frequência em cursos de atualização. As associações e sindicatos docentes, em alguns Estados (São Paulo, Rio de Janeiro, Minas Gerais, Rio Grande do Sul), passaram a organizar atos públicos com a participação de professores de diferentes segmentos primário e secundário da rede pública e particular e, em alguns casos, chegou-se a recorrer à greve, o que causou grande estranheza por se considerar uma atitude incompativel com a nobreza da sua missão. 
De acordo com as autoras, entretanto, ao reconhecer a importância da recompensa financeira da docência, esse tipo de movimentação acabou por reforçar a imagem do professor como um profissional que precisava ser condignamente remunerado para exercer a sua função. Durante as décadas de 60 e 70 muitas professoras assumiram o papel de autonomia e voz na família, seus salários deixaram de apenas complementar os vencimentos dos maridos. Todos esses aspectos impuseram mudanças na imagem profissional docente, no conhecimento especializado da categoria e nas condições de exercício do magistério.

\section{CURSO NORMAL RURAL: instalação e sujeitos}

A história do Colégio Nossa Senhora Auxiliadora remete ao início do desenvolvimento da educação na cidade de Petrolina. Estava situado na Praça Maria Auxiliadora, no centro da cidade. Foi fundado em abril de 1926, por Dom Antônio Maria Malan, o primeiro bispo de Petrolina, e sua direção foi entregue às freiras salesianas da congregação das filhas de Maria Auxiliadora. É uma instituição que já nasce com o compromisso de atender ao público feminino da região, com regime de internato, externato e semi-internato, sob uma orientação católica que, na visão de Dom Malan, era essencial para a formação cidadã.

Destaca-se a importância dos esforços do trabalho das seis freiras da Ordem Salesiana trazidas por Dom Malan, ao chegar à Petrolina, com a missão da instalação do colégio e também para a criação do primeiro curso de formação de professores da região, o "Curso Normal Rural", com a finalidade de formar professoras para atuar tanto na área urbana quanto na zona rural.

As primeiras missionárias traziam na bagagem uma imagem de Nossa Senhora Auxiliadora com a determinação de difundir no sertão pernambucano a pedagogia de São João Bosco e Madre Mazzarello:

Cheias de esperanças, aqui chegaram: Irmã Modesta Martinelli, diretora, Irmã Elizabeth, Irmã Irene Oria, Irmã Salomé Ferreira, Irmã Feliciana Bongianini, Irmã Leontine Ichverza. No início, enfrentaram muitas dificuldades: a cidade atrasada, casa que pertencia ao Cel. José Rabelo Padilha era desprovida de móveis, faziam refeição na casa de D. Daria Padilha de Souza, vizinha do Colégio, e recebeu mobílias emprestadas do Sr. Alcides Padilha, prefeito da cidade (AUXILIADORA, ${ }^{6} 2006$, p. 6).

O jornal O Pharol em 21 de abril de 1926, publicou texto intitulado "A instalação, nessa cidade, de um estabelecimento modelar. O que é o Colégio N. S Auxiliadora Dirigido Pelas Primeiras Salesianas". Em 5 de abril de 1926 tiveram início oficialmente as aulas do Colégio Nossa Senhora Auxiliadora. O Pharol' diz:

O "Collegio N. S. Auxiliadora", que adopta os methodos modelares de ensino, dispõe de preceptoras, cuja competência profissional não teme realização, quer sob o ponto de vista da instrução cientifica e religiosa, quer sob o de línguas, e, para prova desta

\footnotetext{
Neste livro "80 anos do Auxiliadora" queremos deixar gravada a lembrança de tantas pessoas que fizeram e que fazem parte da família salesiana. Da Madre Geral do Instituto das Filhas de Maria Auxiliadora, Diretoras, ex-alunas normalistas até as mais jovens de 5a séries que participaram do Concurso Literário "Auxiliadora em prosa e verso" (AUXILIADORA, 2006, p. 3).

7 Nas transcrições dos textos dos jornais da época conserva-se a linguagem como escrita nos mesmos.
} 
assertiva, installado no melhor prédio da cidade e obedecendo a todos os requisitos de hygiene, o Collegio está apto para receber alunas internas, semi-internas e externas, constituindo, destarte, um empreendimento que nós devemos honrar. Marca na história, não de Petrolina, não de Pernambuco, e sim do Brasil [...] de parabéns, pois, está nossa querida Petrolina! E não só Petrolina. Todas as localidades, vizinhas ou remotas, devem ufanar-se, porque a instrução se dizima (O PHAROL, 1926, n. 29).

Conforme registrado na reportagem, $O$ Pharol apresenta elementos referentes à grandiosidade do ensino da instituição que superaria as expectativas do povo petrolinense. $O$ jornal informa que em relação às professoras preceptoras, essa docência era exercida pelas freiras, não se aceitando outras pessoas para atuarem na escola nesse período.

O desejo de Dom Malan era transformar o Auxiliadora em uma Escola Normal, para formar professoras primárias que atuariam na região. Era uma questão de tempo, como diria o jornal: "Basta dizer que em breve, terá sua equiparação à Eschola Normal do Estado" (O Pharol, 1926, n. 29). "Assim, no dia 02 de fevereiro de 1929, após três anos da criação do colégio, o Bispo Dom Malan anunciou a abertura oficial do Curso Normal Rural, com uma turma de apenas 9 (nove) alunas" (BANDEIRA, 2018, p. 28).

$O$ referido curso funcionaria no Colégio Auxiliadora como um anexo da Escola Normal Oficial de Pernambuco, localizada em Recife, para posteriormente ser equiparado à Escola Normal. No dia 23 de fevereiro de 1930 Dom Malan consegue do governo do Estado, mediante decreto estadual, a equiparação da Escola Normal Nossa Senhora Auxiliadora à Escola Normal do Estado.

Em se tratando das Escolas Normais Rurais de Pernambuco, no quadro a seguir apresenta-se um quantitativo de 15 Escolas Normais Rurais no interior .

Quadro 1 - Escolas Normais Rurais ${ }^{8}$ de Pernambuco na década de 30

\begin{tabular}{|c|l|c|}
\hline 1 & E. N. R. Nossa Senhora Auxiliadora - Petrolina & 1936 \\
\hline 2 & E. N. R. Colégio da Sagrada Família - Goiana & 1936 \\
\hline 3 & E. N. R. de Palmares - Palmares & 1936 \\
\hline 4 & E. N. R. Colégio de Vila Bela - Vila Bela & 1936 \\
\hline 5 & E. N. R. de Floresta - Floresta & 1936 \\
\hline 6 & E. N. R. Salgueiro - Salgueiro & 1936 \\
\hline 7 & E. N. R. Omília Câmara - Sanharó & 1936 \\
\hline 8 & E. N. R. Nossa Senhora de Lourdes - Gravatá & 1937 \\
\hline 9 & E. N. R. Garanhuns - Garanhuns & 1937 \\
\hline 10 & E. N. R. Colégio Santa Christina - Nazaré & 1937 \\
\hline 11 & E. N. R. Nossa Senhora Do Bom Conselho - Bom Conselho & 1938 \\
\hline 12 & E. N. R. Colégio Regina Coeli - Limoeiro & 1938 \\
\hline 13 & E. N. R. Colégio Dom Bosco - Lagoa de Baixo & 1938 \\
\hline 14 & E. N. R. Imaculada Conceição - Sertânia & 1938 \\
\hline 15 & E. N. R. Nossa Senhora da Graça - Vitória & 1938 \\
\hline
\end{tabular}

Fonte:(Silva, 2016 apud BANDEIRA, 2018, p. 40).

\footnotetext{
As datas das escolas normais rurais referem-se ao ano em que essas foram equiparadas, passando a exercer a função de Escola Normal Rural, que ocorria após um ano de inspeção, conforme as normas impostas pela Diretoria Técnica de Educação (RELATÓRIOS DA SECRETARIA DE EDUCAÇÃO, 1930-1940).
} 
De acordo com a análise do Quadro 1, fica estabelecido que no Estado de Pernambuco a primeira "Escola Normal Rural" foi a do Colégio Nossa Senhora Auxiliadora no ano de 1936 e, a partir daí, foram surgindo outras Escolas Normais, em outras localidades, conforme apresenta o quadro.

No dia 6 de dezembro de 1931 é importante destacar a conclusão da primeira turma de professorandas da Escola Normal Nossa Senhora Auxiliadora, sendo então formadas:

Laura do Nascimento, Vande de Souza Paulo, Maria Carlota de Possídio Coelho, Laura de Possídio Coelho, Armênia Guerra Moreira, Odete Sampaio Gomes, Elita da Silveira Coelho, Eunice Lopes de Almeida e Maria de Lourdes Gravatá. E em 1934 cola grau a segunda turma, no total de 14 neo-professoras (LUZ, 1995, p. 128).

Com o reconhecimento do Estado e com o funcionamento como anexo da Escola Normal oficial, segundo Bandeira (2018, p. 43), "O currículo se estabiliza e passa a ser nomeado com duração de 3 (três) anos". Com o advento da reforma de 1933, o curso sofreu uma nova reformulação, com o aumento da sua duração, passando a ocorrer em 4 (quatro) anos.

Ainda nessa linha de pensamento, é importante ressaltar que em qualquer conceituação de currículo, este sempre está comprometido com algum tipo de poder, pois não existe neutralidade do currículo, ele é o veículo de ideologia, da filosofia e da intencionalidade educacional. Para Sacristan (2000):

O currículo é uma práxis antes que um objeto estático emanado de um modelo coerente de pensar a educação ou as aprendizagens necessárias das crianças e dos jovens, que tampouco se esgota na parte explícita do projeto de socialização cultural nas escolas. É uma prática, expressão da função socializadora e cultural que determina que a instituição tem que reagrupar em torno dela uma série de subsistemas ou práticas diversas, entre as quais se encontra a prática pedagógica desenvolvida em instituições escolares que comumente chamamos de ensino. 0 currículo é uma prática na qual se estabelece diálogo, por assim dizer, entre agentes sociais, elementos técnicos, alunos que reagem frente a ele, professores que $o$ modelam (SACRISTAN, 2000 apud MENEZES; ARAÚJO, 2007, p. 34).

É justamente na construção ou na elaboração dos modelos e das propostas curriculares que se define que tipo de sociedade e de cidadão se quer construir, o que a escola faz, para quem faz ou deixa de fazer. É também na construção ou definição das propostas que são selecionados conteúdos, que vão ajudar as pessoas a entenderem melhor a sua história e a compreenderem o mundo que as cerca.

Nessa direção é importante considerar, segundo Reis (2009), que:

O currículo contextualizado precisa ser compreendido como um campo de transgressões e insurgência epistemológicas, não limitantes ao contexto, mas sempre chegando ou partindo deste. Somente assim será possível estabelecer e construir a comunicação dos saberes locais com os globais, evitando assim que se caia na deturpação que professa o currículo como veículo de transmissão de verdades inquestionáveis, absolutas, em sim mesmo (p. 34).

Um exemplo significativo dessa análise sobre o currículo destaca-se no quadro a seguir, das disciplinas ofertadas durante os quatro anos do Curso Normal Rural, uma vez que se percebe a organização do currículo do colégio a partir da inclusão de novas disciplinas já no último ano do curso e ao mesmo tempo atendendo melhor à realidade das aulas no mundo que as cerca. 
Quadro 2 - Comparativo das disciplinas do Curso Rural Normal do Colégio Nossa Senhora Auxiliadora entre 1945 e 1949

\begin{tabular}{|l|l|}
\hline Curso & Normal Rural \\
\hline Duração & 4 anos \\
\hline 1o Ano & $\begin{array}{l}\text { Religião, Português, Francês, Matemática, Geografia Geral, História Geral, Música } \\
\text { e Canto, Educação Física. }\end{array}$ \\
\hline 20 Ano & $\begin{array}{l}\text { Religião, Português, Francês, Inglês, Matemática, História do Brasil, Geografia, do } \\
\text { Brasil, Desenho, Pintura, Educação Física. }\end{array}$ \\
\hline 3o Ano & $\begin{array}{l}\text { Religião, Português, Inglês, Matemática, História Natural, Física, Química, Desenho, } \\
\text { Educação Física. }\end{array}$ \\
\hline 40 Ano & $\begin{array}{l}\text { Religião, Português, Biologia, Psicologia, Higiene, Metodologia, Agricultura, Música } \\
\text { e Canto, Desenho, Artes, Prática de Ensino, Sociologia e Educação Física. }\end{array}$ \\
\hline
\end{tabular}

Fonte: Quadro elaborado por Rosa Santos Mendes da Silva, com base no Histórico Escolar de Cremilda Sá Ledo, ex-aluna do Curso Normal Rural (2018).

Vale salientar, no entanto, que, sobre a disciplina de Agricultura, define-se:

[...] os temas referentes à agricultura figuravam em currículos de formação de professores não na perspectiva de que havia saberes doutos em agricultura, os quais eram transformados em saberes a ensinar e que estes, por sua vez, ali deveriam estar por compor o perfil de profissional docente intencionado, ou seja, que tais conteúdos precisassem estar relacionados permanentemente com o seu ensino em escolas de primeiras letras. Levantamos a hipótese de que Agricultura figurava no currículo, pois Geometria, Desenho Linear, Ciências Naturais, Mineralogia e Geologia, ou outros conteúdos, para serem transpostos do plano de conhecimentos científicos para conhecimentos escolarizados, precisavam ser contextualizados, organizados com alguma pertinência em relação à realidade concreta e não apenas em forma de saberes abstratos. Por isso a menção à Agricultura e elementos do mundo rural (WERL; BRITO, 2006 apud BANDEIRA, 2018, p. 19).

Assim, vale ressaltar, a realidade da organização do curso Normal Rural referente ao pagamento, conforme relata Bandeira (2018, p. 43): "[...] de caráter privado e confessional, o Curso Normal da instituição atendeu apenas a uma pequena parcela da população, pois cobrava uma mensalidade de valor muito alto, principalmente quando se tratava do internato".

Em relação à mensalidade ${ }^{9}$ das alunas internas, semi-internas e externas, o Pharol dispõe uma coluna exclusiva sobre o assunto:

A mensalidade para as alunas internas é de $100 \$ 000$. Deve ser paga adeantadamente em duas prestações iguaes, uma no acto da matricula e a outra em princípios de Julho. Joia annual de $50 \$ 000$, para a conservação do mobiliário. A lavagem de roupa no estabelecimento é de $12 \$ 000$ mensaes. As lições de piano, pintura, pyrogravura, flores, dactylographia e línguas pagam-se à razão de $20 \$ 000$ mensaes.

A mensalidade das semi-internas é de $50 \$ 000$ e a jóia annual de $10 \$ 000$.

A mensalidade das externas é de $15 \$ 000$. Todas pagaram uma jóia de $10 \$ 000$ (O PHAROL, 1926, n. 25).

\footnotetext{
Neste período, a moeda brasileira era denominada de Mil Réis, lendo-se da seguinte forma: $20 \$ 000$ (Vinte mil réis); $50 \$ 000$ (Cinquenta mil réis); $100 \$ 000$ (Cem mil réis) e, assim sucessivamente. Essa moeda vigorou no Brasil de 8 de outubro de 1833 a 31 de outubro de 1942, totalizando 109 anos de adoção.
} 
O anúncio do jornal apresenta a diferença de valores pagos pelas alunas que optaram por uma das três modalidades, além de exibir as normas do estabelecimento para as alunas internas com o intuito de garantir maior comodidade. A partir, contudo, da análise dos valores pagos pelos pais das normalistas do curso, fica clara a relação de poder de classe que existia na cidade, pelo fato de que a mensalidade das alunas internas era um valor alto e só era aluna interna quem tinha condição de pagar, restando às que não se enquadravam neste quesito a opção pelo externato.

Vale destacar que só a elite teria condições de custear essas despesas. Logo, o CNSA passou a atrair alunas de outras localidades do interior do Nordeste, e entre os Estados que mais se destacaram estavam o Piauí e a Bahia.

$\mathrm{Na}$ análise do livro "80 anos Auxiliadora" (2006, p. 9): “[...] após a equiparação oficial do Colégio Normal Rural, nos anos seguintes o Colégio Nossa Auxiliadora entrega à sociedade de Pernambuco, Bahia e Piauí, 14 professoras recém-formadas. Em 1939, o Estado da Bahia reconhece o diploma das professoras formadas pelo colégio".

Em 1936, sob a direção da irmã Bibi Ana Marçal, o CNSA já ministrava os seguintes cursos:

Primário, preliminar, fundamental e o curso normal rural, passando esse estabelecimento a se chamar-se Escola Normal e Ginásio Nossa Senhora Auxiliadora, contando com os seguintes professores: Dr. João Cardoso de Sá, João Rodrigues Leal, Dr. Epaminondas Albuquerque e José Rubens, além das irmãs salesianas: Irmã Carlota Possídio, Maria de Lourdes Velloso, Irmã Laura Possídio e as senhoritas Laura Nascimento Coelho e Rosalina Macedo (BRITO 1995, p. 258).

Uma vez que os cursos contavam com um público de 23 alunas externas e 40 internas, estas últimas eram geralmente das cidades ribeirinhas e algumas do Piauí, de Pernambuco e da Bahia.

Figura 1 - Reportagem de "O Pharol", sobre a divulgação das matrículas da Escola Normal Nossa Senhora Auxiliadora

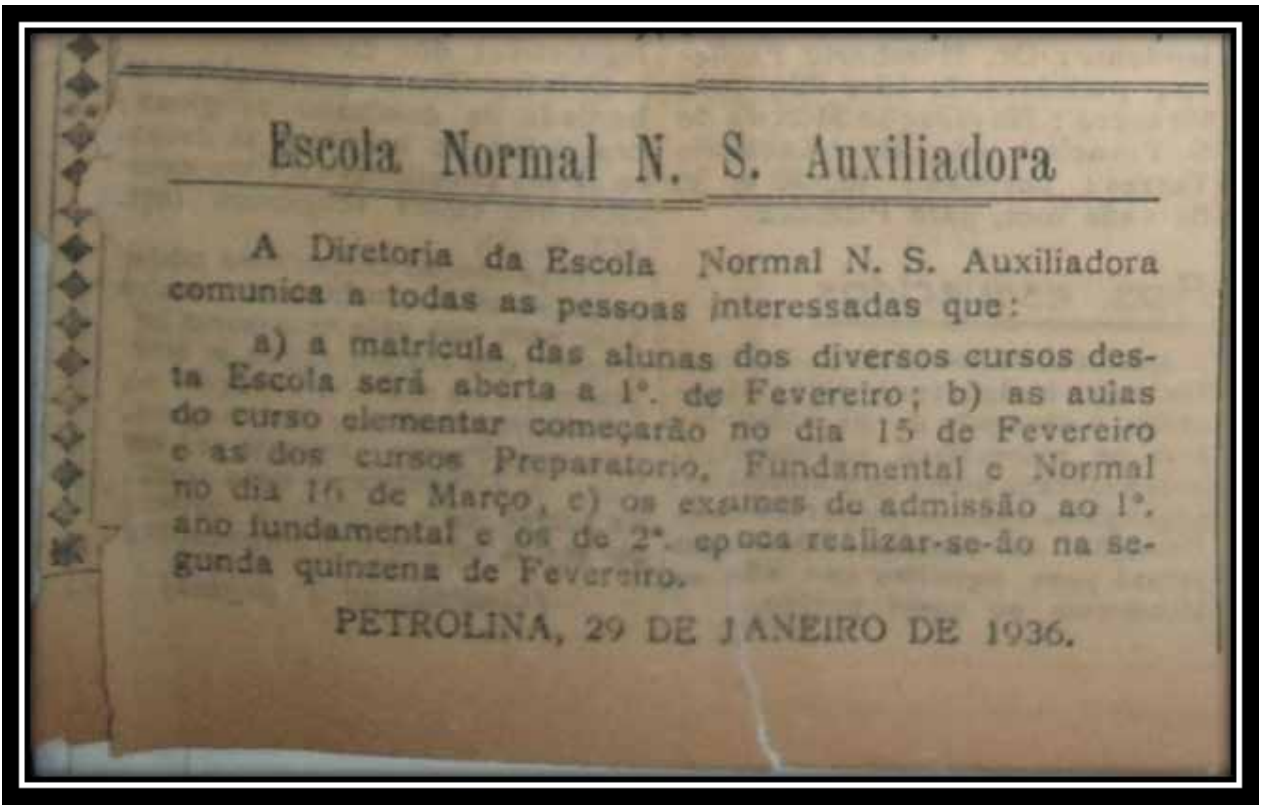

Fonte: Arquivo Departamento de Comunicação - Uneb. 
A foto anterior é uma notícia sobre a "Escola Normal N. S Auxiliadora" publicada pelo jornal $O$ Pharol no dia 29 de janeiro de 1936. Em nota do jornal observa-se a divulgação da matrícula das alunas nos diversos cursos, tendo em vista que a escola nesse ano já avança no desenvolvimento dos cursos.

É importante destacar uma reportagem do O Pharol em 1935 que informa a "Formatura da Nova Turma de Professoras". Em nota o jornal destaca:

No sábado 30 de Novembro, effectuou-se nesta cidade a solenidade da formatura das novas professoras que terminaram o seu curso na Escola Normal. [...] quando as professorandas acompanhadas dos seus paraninfos deram entrada no recinto do Theatro 21 de Setembro, executou o Hymno Nacional, ouvindo-se calorosas palmas [...]. Foi oradora da turma a alumna laureada, senhorita Olga Menezes, cujo discurso brilhante publicaremos na próxima edição. Depois da entrega de diplomas às professorandas senhoras Olga Menezes, Maria de Lourdes Pereira Sant Anna, Lucy Madeira, Margarida Souza e Filonila Aquino, usou da palavra o Exmo. Sr. D. Idilio Soares, saudando-as, em virtude do estado de saúde do Prof. João Leal não Ihe permitir a solemnidade. [...] encerrou-se a cerimonia com uma belíssima scena allegorica em que tornaram parte várias alumnas e ex- alumnas do estabelecimento. Dando parabéns à Escola Normal N. S Auxiliadora o Pharol rende homenagens à brilhante plêiade de neo-professoras e as suas exmas. famílias (O PHAROL, 1935, n. 12).

De acordo com o jornal, as pessoas que compareceram à formatura participaram das alegrias das formandas ao receberem o diploma. Os pais de Maria de Lourdes Pereira Sant'Anna ofereceram uma animada festa na sua residência para familiares e amigos próximos da família, com espumantes e licores servidos aos presentes.

Figura 2 - Reportagem O Pharol, ${ }^{11}$ sobre o "Resultado das provas parciais do mês de julho de 1935" da Escola Normal Nossa Senhora Auxiliadora

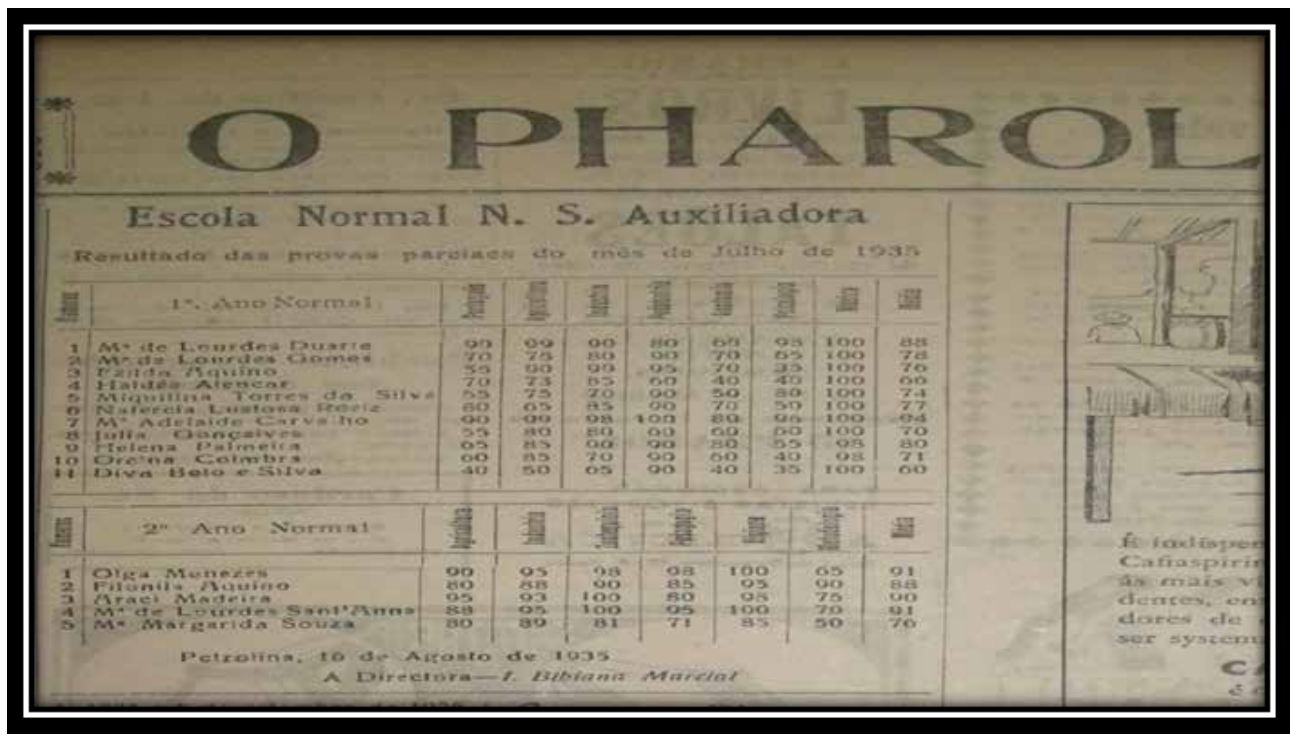

Fonte: Arquivo Departamento de Comunicações - DCH III, UNEB.

\footnotetext{
${ }^{10}$ O jornal O Pharol reportava Escola Normal Nossa Senhora Auxiliadora, mas a nomenclatura da instituição é Colégio Nossa Senhora Auxiliadora.

${ }^{11}$ Por algum tempo o "PHAROL", jornal local, publicava as notas das provas. Nos roteiros de três dias era observado silêncio rigoroso (AUXILIADORA, 2006, p. 84).
} 
Com este expediente, o jornal informa as notas das provas parciais das alunas normalistas da terceira turma do ano de 1935 , tendo como disciplinas referentes ao 1 으 e 2 은 anos: Português, Agricultura, Indústria, Pedagogia, Anatomia, Psicologia, Música, Higiene, Metodologia e Zootecnia.

Concluímos que, no decorrer do trabalho desenvolvido pelas irmãs salesianas em preparar as jovens para atuar no ensino em Petrolina, houve um quantitativo satisfatório de formadas. Conforme analisa Brito (1995), de 1931 a 1988 a Escola Normal Nossa Senhora Auxiliadora teve o privilégio de entregar o diploma a 1.327 professoras, em 54 turmas. Em 1989 é suspenso o curso de Magistério e se inaugura o Ginásio de Esporte.

\section{CONSIDERAÇÕES FINAIS}

A pesquisa buscou resgatar a gênese de um colégio particular de ensino confessional, que foi projeto do primeiro bispo da cidade de Petrolina/PE, desenvolvido pelas irmãs salesianas. Esse colégio foi de grande relevância para a cidade, pelo fato de ter iniciado com o curso primário e logo após ter instalado o primeiro curso Normal Rural de formação de professores, contribuindo para o desenvolvimento da educação privada e expansão do atendimento de uma demanda da educação pública, uma vez que a missão do curso era formar jovens normalistas para depois atuarem nas localidades das áreas urbana e rural que necessitavam de professoras alfabetizadoras.

Ao estudar a história dessa instituição não se teve o propósito de responder somente ao que pretendia a pesquisa, mas de dispor à geração atual o entendimento do curso Normal Rural e, também, apresentar os personagens que fizeram parte dessa trajetória educacional.

Diante dessas considerações, percebemos que há muito ainda para revelar sobre a organização do curso Normal Rural, sobre o currículo, o trabalho que foi desenvolvido pelas irmãs salesianas e a atuação das normalistas nas escolas.

Destaca-se, por fim, que é impossível dissociar o papel do CNSA do desenvolvimento da região de Petrolina/PE, pois tanto a cidade como o colégio vão desempenhando o papel de propulsores dos novos tempos da educação, pois assume o papel de formar docentes que iriam ser o fundamento das escolas que atenderiam as regiões rurais do entorno da cidade, que a partir deste marco recebiam as suas primeiras normalistas com diploma de professoras.

Outro aspecto a se destacar a respeito da cidade de Petrolina - PE - é que, saindo apenas de uma passagem de Juazeiro/BA, desponta na sua trajetória histórica e desenvolvimentista como um dos grandes expoentes do interior de Pernambuco. Assim, evidencia-se que, nesse caso, torna-se impossível separar o processo de desenvolvimento da educação do processo de desenvolvimento regional.

\section{REFERÊNCIAS}

AUXILIADORA. Antologia 80 anos. Petrolina: CNSA, 2006.

BANDEIRA, Emerson Sávio Leal. Entre propostas e programas: análise da implementação do curso normal rural no Colégio Nossa Senhora Auxiliadora. 2018. Trabalho (Conclusão de Curso) - Universidade do Estado de Pernambuco, Petrolina, 2018. 
BRASIL. Decreto-lei no 8.530, de 2 de janeiro de 1946. Lei Orgânica do Ensino Normal. Disponível em: http://www.soleis.adv.br/leiorganicaensinonormal.htm . Acesso em: 20 dez. 2020.

BRITO, Maria Creusa de Sá e. Educação em Petrolina. Petrolina: origem, fatos, vida, uma história. Petrolina: Tribuna do Sertão, 1995.

CARVAS, Giovanna Maria Abrantes. A educação salesiana na cidade de Ponte Nova - Minas Gerais e a formação de professoras na Primeira República. 2015. Dissertação (Mestrado) - Universidade Federal de Viçosa, 2015. Disponível em: http://www.poseducacao.ufv.br/wpcontent/uploads/2017/02/Disserta\%C3\%A7\%C3\%A3o-Giovanna-Carvas-2015.pdf Acesso em: 20 dez. 2020.

LE GOFF, Jacques. História e memória. Tradução Bernardo Leitão et al. 2. ed. Campinas: Unicamp, 1994. LUGLI, Rosário S. Genta. O trabalho docente no Brasil: o discurso dos centros regionais de pesquisa educacional e das entidades representativas do magistério (1950-1971). 2002. Tese (Doutorado) - Universidade de São Paulo, São Paulo, 2002.

LUZ, Marta. Petrolina - a terra dos impossíveis. Cronologia histórica cultural: Petrolina: Prefeitura Municipal de Petrolina, 1995.

MENEZES, A. C.; ARAÚJO, L. Currículo, contextualização e complexidade: espaço de interlocução de diferentes saberes. In: RESAB. Currículo, contextualização e complexidade: elementos para se pensar a escola no semi-árido. Juazeiro: Selo Editorial Resab, 2007.

NETO, Raquel A. Formação de professores primário no Vale do são Francisco: desafios e perspectivas da profissão (1950-1970). Trabalho de Conclusão de Curso de Pedagogia. 2016 (Universidade de Pernambuco). Petrolina: UPE, 2016.

O PHAROL, Petrolina, ano XII, 1926.

O PHAROL, Petrolina, ano XXI, 1935.

O PHAROL, Petrolina, ano XXII, 1936.

PERES, Pedro Correa de Araújo. A emergência da profissão docente no espaço público estatal: do mestre-escola ao professor público primário em Pernambuco. 2006. Dissertação (Mestrado em História) - Universidade Federal de Pernambuco, Programa de Pós-Graduação em História, Recife, 2006.

RAMOS, Lusinete. A união das ex-alunas salesianas através do tempo: um recorte histórico. Petrolina, 2016.

REIS, Edmerson dos Santos. A contextualização dos conhecimentos didáticos e saberes escolares nos processos de reorientação curricular nas escolas do campo. 2009. Tese (Doutorado em Educação) - Universidade Federal da Bahia, Ufba, Salvador, 2009.

ROCHA, Cícera M. P. Ser professora no semiárido nordestino: a trajetória de Yolanda de Almeida (19601970). In: Encontro Norte e Nordeste de História da Educação. 5. Teresina/PI. Anais [...]. Teresina/PI, 2014. SANTOS, Nivalda Menezes. O celibato pedagógico feminino em Sergipe nas três primeiras décadas do século XX: uma análise a partir da trajetória de Leonor Telles de Menezes. 2006. Dissertação (Mestrado) Universidade Federal do Sergipe, 2006.

TANURI, Leonor Maria. História da formação de professores. Revista Brasileira de Educação, Campinas, SP, v. 14, p. 61-88, 2000.

VICENTINI, Paula Perin; LUGLI, Rosario Genta. História da profissão docente no Brasil: representações em disputa. São Paulo: Cortez, 2009.

VASCONCELOS, Maria Celi Chaves. Um estudo sobre a gênese da profissão docente. Revista Poiésis, v. 2, n. 2, p. 57-72, jan./dez. 2004. 